\title{
Modeling of nursing care-associated airborne transmission of SARS-CoV-2 in a real-world hospital setting
}

\author{
Attila Nagy $(\mathbb{D} \cdot$ Alpár Horváth · Árpád Farkas · Péter Füri · Tamás Erdélyi • \\ Balázs G. Madas • Aladár Czitrovszky • Béla Merkely • Attila Szabó • \\ Zoltán Ungvári • Veronika Müller
}

Received: 4 November 2021 / Accepted: 29 December 2021 / Published online: 5 January 2022

(C) The Author(s) 2022

\begin{abstract}
Respiratory transmission of SARS$\mathrm{CoV}-2$ from one older patient to another by airborne mechanisms in hospital and nursing home settings represents an important health challenge during the COVID-19 pandemic. However, the factors that influence the concentration of respiratory droplets and aerosols that potentially contribute to hospital- and nursing care-associated transmission of SARS-CoV-2
\end{abstract}

A. Nagy $(\bowtie) \cdot$ A. Czitrovszky

Department of Applied and Nonlinear Optics, Wigner

Research Centre for Physics, Konkoly-Thege Miklós st.

29-33, Budapest, Hungary

A. Horváth · T. Erdélyi · V. Müller

Department of Pulmonology, Semmelweis University,

Budapest, Hungary

Á. Farkas · P. Füri · B. G. Madas

Environmental Physics Department, Centre for Energy

Research, Budapest, Hungary

A. Czitrovszky

Envi-Tech Ltd, Budapest, Hungary

B. Merkely

Heart and Vascular Centre, Semmelweis University, Budapest, Hungary

A. Szabó

1st Department of Pediatrics Semmelweis University,

Budapest, Hungary

A. Szabó

Clinical Center, Semmelweis University, Budapest,

Hungary are not well understood. To assess the effect of health care professional (HCP) and patient activity on size and concentration of airborne particles, an optical particle counter was placed (for $24 \mathrm{~h}$ ) in the head position of an empty bed in the hospital room of a patient admitted from the nursing home with confirmed COVID-19. The type and duration of the activity, as well as the number of HCPs providing patient care,

\footnotetext{
Z. Ungvári

Vascular Cognitive Impairment and Neurodegeneration Program, Oklahoma Center for Geroscience and Healthy Brain Aging, Department of Biochemistry \& Molecular Biology, University of Oklahoma Health Sciences Center, Oklahoma City, OK 731042, USA

Z. Ungvári

Peggy and Charles Stephenson Cancer Center, Oklahoma City, OK 73104, USA

Z. Ungvári

Department of Health Promotion Sciences, College of Public Health, University of Oklahoma Health Sciences Center, Oklahoma City, OK, USA

Z. Ungvári

International Training Program in Geroscience, Doctoral School of Basic and Translational Medicine/Department of Public Health, Semmelweis University, Budapest, Hungary
} 
were recorded. Concentration changes associated with specific activities were determined, and airway deposition modeling was performed using these data. Thirty-one activities were recorded, and six representative ones were selected for deposition modeling, including patient's activities (coughing, movements, etc.), diagnostic and therapeutic interventions (e.g., diagnostic tests and drug administration), as well as nursing patient care (e.g., bedding and hygiene). The increase in particle concentration of all sizes was sensitive to the type of activity. Increases in supermicron particle concentration were associated with the number of HCPs $(r=0.66 ; p<0.05)$ and the duration of activity $(r=0.82 ; p<0.05)$, while submicron particles increased with all activities, mainly during the daytime. Based on simulations, the number of particles deposited in unit time was the highest in the acinar region, while deposition density rate (number $/ \mathrm{cm}^{2}$ / min) was the highest in the upper airways. In conclusion, even short periods of HCP-patient interaction and minimal patient activity in a hospital room or nursing home bedroom may significantly increase the concentration of submicron particles mainly depositing in the acinar regions, while mainly nursing activities increase the concentration of supermicron particles depositing in larger airways of the adjacent bed patient. Our data emphasize the need for effective interventions to limit hospital- and nursing care-associated transmission of SARS-CoV-2 and other respiratory pathogens (including viral pathogens, such as rhinoviruses, respiratory syncytial virus, influenza virus, parainfluenza virus and adenoviruses, and bacterial and fungal pathogens).

Keywords Airborne transmission - Aerosol measurement $\cdot$ Lung deposition · Aerosol dispersion . Nursing $\cdot$ Elderly $\cdot$ SARS-CoV-2

\section{Introduction}

Coronavirus disease 2019 (COVID-19) caused by infection with the novel coronavirus SARS-CoV-2 (severe acute respiratory syndrome-coronavirus 2) resulted in a deadly pandemic [1]. COVID-19 has caused more than 5.3 million deaths worldwide to date [2]. Importantly, SARS-CoV-2 infection causes worse outcomes (e.g., increased risk of hospitalization, intensive care unit admission, and invasive mechanical ventilation) and results in a significantly higher mortality rate in older adults [1]. Most of COVID-19 deaths in the USA have been among adults 65 years and older $[1,3]$.

The principal mode of infection is through exposure to respiratory fluids carrying infectious SARSCoV-2 virus particles [4]. There is strong evidence that transmission of SARS-CoV-2 may occur through close contact with an infected person through airborne particles (including both respiratory droplets and aerosols) [4, 5]. The view is emerging that infected people, by breathing, talking, sneezing, and coughing as well as by medical procedures, release airborne particles of different sizes consisting of respiratory fluids carrying an infectious dose of viable SARSCoV-2 $[4,5]$. While the larger droplets settle out of the air rapidly, the smallest droplets and fine aerosol particles remain suspended in the air for an extended period of time [4, 5]. SARS-CoV-2 is transmitted by inhalation of air carrying airborne particles of different sizes that contain infectious virus $[4,5]$; by deposition of these virus-loaded particles onto exposed mucous membranes (e.g., in the nose, mouth, and eye) and by touching mucous membranes with the hands soiled by exhaled respiratory fluids (including exhaled virus-carrying particles settled on inanimate surfaces) [4, 5]. Current research projects focus on several aspects of these processes, from understanding the physics of the formation and deposition of airborne particles and to identifying factors that impact their size and concentrations. To date, multiple physiological and environmental factors have been identified, which likely affect the respiratory transmission of SARS-CoV-2. Among them, crowding and sharing common facilities as well as indoor settings with inadequate ventilation or air handling are known to modulate the concentration of airborne particles and are thus risk factors for transmission of SARS-CoV-2 [6]. Other critical factors that determine the risk of respiratory transmission of SARS-CoV-2 include the distance from the source, increased exhalation by the infected person (e.g., during physical exertion and singing), air flow physics, and length of exposure [4]. The dynamic processes influencing the movement and size of the aforementioned airborne particles are of special importance. Observing and monitoring the presence and transport of airborne particles is particularly important in closed spaces, such as hospital rooms. 
Older adults living or staying in congregate settings, such as nursing home bedrooms and hospital rooms, are at an especially high risk of respiratory transmission of SARS-CoV-2 by airborne mechanisms. These are typically enclosed spaces without effective removal of airborne particles where patients stay for an extended period of time. Moreover, older nursing home residents are frequently frail with a dysregulated immune function (immunosenescence [6-8]) that contributes to their increased susceptibility to infection [1,9-11]. As a result, the COVID19 pandemic has devastated nursing homes in the USA [12-15] as well as the European Union [16, 17]. Although only around 0.4 to $0.7 \%$ of the total population of the USA and the European Union live in nursing and residential care facilities, long-termcare facility deaths have accounted for $\sim 25$ to $74 \%$ of the documented deaths due to COVID-19 in many regions on both contients $[14,18,19]$. In the USA, over $8 \%$ of people who live in long-term-care facilities, which include nursing homes, assisted living and other long-term care facilities, have died of COVID19 (for nursing homes alone, the figure is close to $10 \%$ ) [20]. Before COVID-19, nursing home associated respiratory infections already represented an important health challenge [21-25].

Healthcare professionals (HCPs) are essential workers defined as persons serving in health care settings who are directly or indirectly exposed to patients with COVID-19 and potentially to infectious materials [26-28]. There is strong evidence that HCPs could play a significant and multifaceted role in pathogen transmission [29, 30].

The present study was designed to determine how the daily activities of HCPs impact the concentration and size distribution of airborne particles in a hospital room housing an elderly patient with COVID-19. To achieve that goal, an optical particle counter was placed (for $24 \mathrm{~h}$ ) in the head position of an empty bed in the hospital room of a confirmed COVID-19 patient admitted from the nursing home. The type and duration of the activity, as well as the number of HCPs providing patient care, were recorded. Concentration changes associated with specific activities were determined. The measured data were also used to quantify the associated risks by applying a lung deposition model of the inhaled particles for individuals needing full medical/nursing support. HCP activities associated with the highest risk of possible airborne particle mediated infection were identified and characterized.

\section{Methods}

Measurements were performed over a 24-h period in a closed patient room (Department of Pulmonology, Semmelweis University, Budapest, Hungary) with one PCR positive COVID-19 patient admitted from a nursing home during the first wave of the pandemic (March-June 2020). This three-bed patient room was selected as the patient was unable to leave the bed needing full medical and nursing support. The layout of the patient room is depicted in Fig. 1. There was no heating, ventilation, and air conditioning in operation due to local public health regulations. The patient room was thoroughly cleaned to prevent resuspension of previously deposited airborne particles. The patient could not tolerate wearing a mask. HCPs wore appropriate personal protective equipment (PPE) all the time, including single-use plastic-based protective clothing, face shields, and N95 respirators, which
Fig. 1 The layout of the three-bed patient room. A Patient with COVID-19 confirmed with PCR test. B Optical particle counter located at the head position of an imagined patient. C Optical particle counter at the foot position of an imagined patient

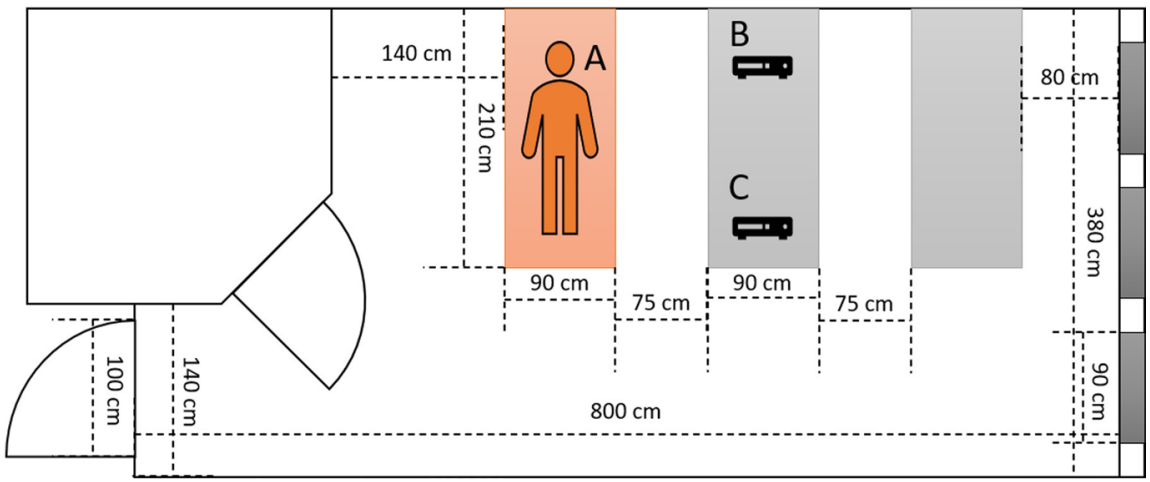


prevented both HCP exposure to respiratory droplets and airborne particles and release of respiratory droplets and airborne particles by the HCPs.

All HCP activities in the room were recorded as follows: activities and number of personnel as well as time spent in the room. Measuring devices were placed on the empty middle bed in the head and feet positions. The measurements were repeated at a later time point in the same room when no patient was present for $24 \mathrm{~h}$ to assess background particle concentrations, confirming stable values during the day without human activity.

The events corresponding to the activities were classified into three categories: A) physician and/or nurse visit for medical diagnostic examinations (e.g., electrocardiogram and ultrasound) and/or therapy administration (e.g., infusion and medication); B) nursing care (e.g., feeding, personal hygiene, bedding, and full patient care); C) patient's activity. While A and B were logged by the medical staff, C was added by post-processing of the data. Aerosol particle concentrations (number/liter) and size distributions were measured by an optical particle counter (OPC - Grimm Aerosoltechnik, Portable Aerosol Spectrometer, model 1.109) for $24 \mathrm{~h}$ with 1-min time resolution. The size distributions were recorded in 31 size bins between 0.25 and $32 \mu \mathrm{m}$. The upper concentration limit $(<5 \%$ coincidence error) of the instrument is 2 million particles/l. For the measurements, we used the radial symmetric sampling head provided by the manufacturer of the OPC. The device can be operated autonomously. It is small $\left(24 \times 13 \times 7 \mathrm{~cm}^{3}\right)$ and quiet, making it suitable for the measurements in a hospital room for a longer time without disturbing the patient and the medical personnel. Concentrations corresponding to the events were calculated by averaging the measured numbers for the events' duration. The baseline concentration was determined by averaging the data from the preceding $5 \mathrm{~min}$ of each activity.

The airway deposition of the particles with the measured size distributions corresponding to the selected activities was simulated by the stochastic lung deposition model [31-33]. The computations refer to particle inhalation without a mask. Nose breathing was assumed with $500 \mathrm{ml}$ tidal volume, $2100 \mathrm{ml}$ functional residual capacity, $1.9 \mathrm{~s}$ inhalation, $0.1 \mathrm{~s}$ breath-hold between inhalation and exhalation, $2.0 \mathrm{~s}$ exhalation, and a $1.0 \mathrm{~s}$ breath-hold after the exhalation, representing quiet breathing at rest (12 breaths/min). The deposition model simulates the airways' asymmetric branching system and provides the fraction and density of particles deposited in different anatomical regions. In order to calculate the density values, the surface of different regions is needed. The extrathoracic airways representing the nasopharyngeal cavity have a relatively small surface (set at $0.047 \mathrm{~m}^{2}$ ). The area of conductive airways from the trachea till respiratory bronchioles, including terminal bronchiole, is smaller (set at $0.47 \mathrm{~m}^{2}$ ) compared to the acinar surface (set at $147 \mathrm{~m}^{2}$ ) [34]. The model has been validated against experimental data as published previously [35, 36].

\section{Results}

Concentration values measured by the two OPC devices revealed that there was no significant difference at the two sampling locations. Separate day background measurements in the same unoccupied room showed that the aerosol particle concentration and size distribution did not change in the absence of human activity.

Figure 2 shows the time dependence of the concentrations in the sub- and supermicron size ranges in the real-world setting representing different activities corresponding to $\mathrm{HCP}$ and patient-generated particle peaks. It can be seen that the total aerosol particle concentration in the hospital room varied between 55,000 and 135,000 particles/l in one day.

Altogether, thirty-one events were logged during the 24 h' period, from which six representative ones were selected in the current study. These six events represent all categories (A, B, and C) and correspond to well-defined peaks on the concentration trends graph (Fig. 2 and Table 1).

The measured size distributions can be modeled by a double peak log-normal distribution. Based on the size bins' contributions to the two modes of the distribution, the instrument's size range can be split into two parts at $1 \mu \mathrm{m}$ diameter, where the particles' properties and their generation mechanisms are significantly different. The majority of the activities in a hospital room contribute to both modes (size ranges) to different extents. Cleaning, bedding, or other significant movements by HCPs contribute more to the 
Fig. 2 Time series of the measured number concentrations in two size bins, below $1 \mu \mathrm{m}$ (orange curve) and above $1 \mu \mathrm{m}$ (blue curve) with 1-min time resolution. The grey rectangles show the six selected events indicating the duration of the activities by their width

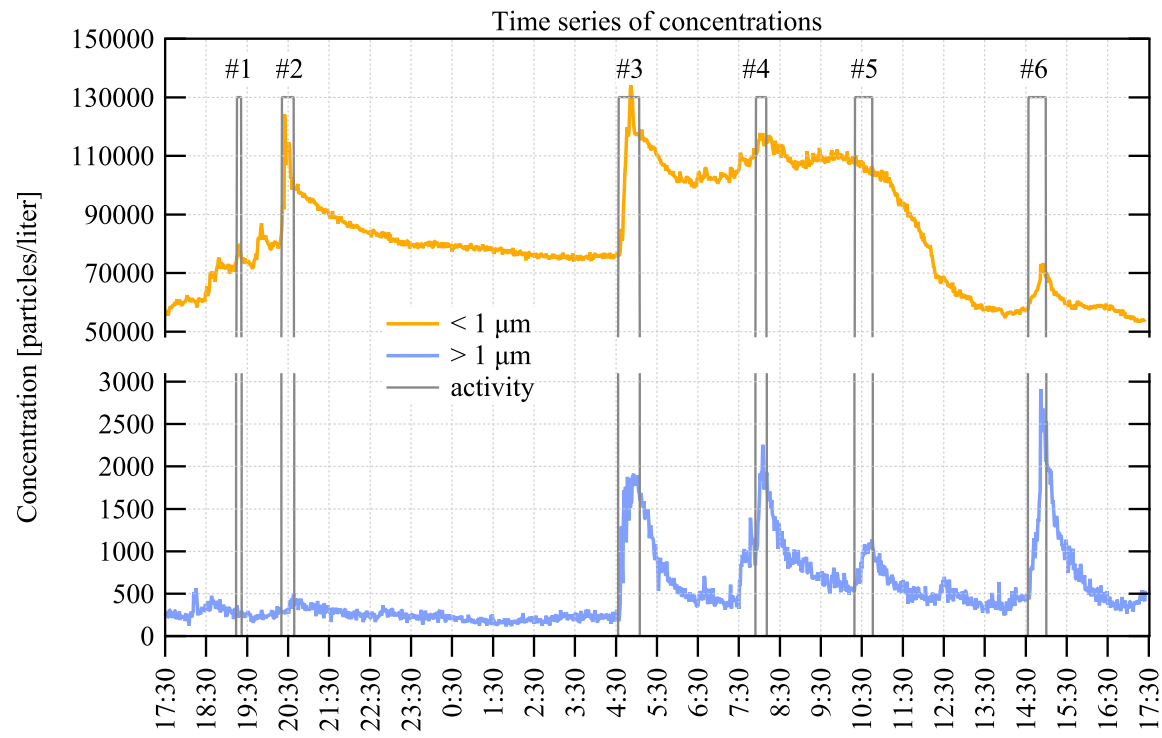

Time

\begin{tabular}{llllllll}
\hline Event No & Category & $\begin{array}{l}\text { No. of } \\
\text { person- } \\
\text { nel }\end{array}$ & $\begin{array}{l}\text { Duration } \\
{[\text { min.] }}\end{array}$ & $\begin{array}{l}\text { Baseline } \\
<1 \mu \mathrm{m}\end{array}$ & $\begin{array}{l}\text { Contribution } \\
<1 \mu \mathrm{m}\end{array}$ & $\begin{array}{l}\text { Baseline } \\
>1 \mu \mathrm{m}\end{array}$ & $\begin{array}{l}\text { Contributio } \\
>1 \mu \mathrm{m}\end{array}$ \\
\hline 1 & $\mathrm{C}$ & 0 & 6 & 71,457 & 5843 & 274 & 0 \\
2 & $\mathrm{~A}$ & 1 & 16 & 79,665 & 26,136 & 281 & 55 \\
3 & B & 2 & 30 & 76,204 & 33,142 & 213 & 1229 \\
4 & A & 2 & 15 & 110,835 & 3682 & 1018 & 658 \\
5 & A & 3 & 28 & 108,454 & 0 & 552 & 346 \\
6 & A and B & 3 & 25 & 57,295 & 7997 & 444 & 1019 \\
\hline
\end{tabular}

Table 1 Description of the selected events with measured baseline concentrations and the events' contributions to the baseline (average number of aerosol particles/l) increases in supermicron sized particles reaching the measurement device.

It can be observed in Fig. 2 that the maxima in the sub-micron and supermicron size ranges do not always overlap. For events \#2, \#3, and \#4, the submicron peak occurs in the first or middle part of the event duration, while in the range above one micron, the maximum (where present) is reached by the end of the event period, which we attribute to air flow dynamics. As soon as the activity ceases, the concentration decreases in the supermicron size range. In event \#6, both maxima occur towards the end of the period; however, there is also a 3-4-min-long difference between them. There was no increase in the concentration above one micron for event \#1 and below one micron for event \#5 associated with the given activities, which might represent differences in particle distribution and disturbance related to specific activities.

In Fig. 2, activities \#3 and \#4 seem to lead to a much slower particle concentration decay than the others. This is explained by the fact that there were other activities shortly after activities \#3 and \#4, which are not shown in the figure, but also affected the particle count.

In general, the larger the number of sampled particles during a given activity, the longer the time of particle concentration decrease to the pre-activity level measured at the position of a neighbor bed patient's head. Table 1 shows the activities' contributions to the baseline concentrations during the six selected events, together with their category, duration, and the number of HCPs in the room. 
Figure 3 shows the events' contributions in the two size ranges on top of the corresponding baseline concentrations. It can be seen that the different events result in different patterns of the contribution added to the baseline value in the two selected size ranges.

For events \#1 and \#2, the supermicron contribution is negligible, while it is significant for events \#3, \#4, $\# 5$, and \#6. For events \#4, \#5, and \#6, the supermicron contributions are comparable or larger than the baseline, while the sub-micron contributions are relatively small. For event \#3, there are significant increments in the concentrations in both size ranges. As our results demonstrate, there is a significant dependence of the particle number on the type of activity. HCP activities related to physician and/or nurse visits for medical diagnostic examinations and nursing care are among the most important events causing the increase in the number of submicron particles. By the same token, activities related to full patient care, but especially bedding, have contributed significantly to the rise of larger particles' concentration in the air.

Besides the type of activity, the concentration of particles may depend on the number of personnel carrying out the given activity and its duration. Our analysis has shown that the increase of submicron particles as a result of different patient and HCP activities (all the monitored activities, not only those selected and marked in Fig. 2) did not correlate with the number of personnel inside the hospital room and correlated only weakly and insignificantly $(p>0.05)$ with

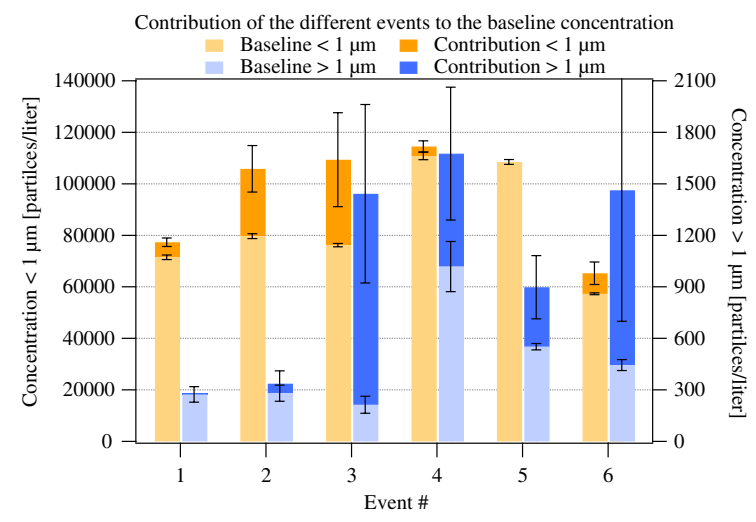

Fig. 3 Contributions on top of the baselines in the two size bins. The baselines are the concentrations preceding the events. The contributions were calculated by subtracting the baseline concentrations from the measured concentrations during the events the duration of the activity. In contrast, the increase of the number of larger particles $(>1 \mu \mathrm{m})$ fairly correlated with the number of HCPs in the room $(r=0.66$, $p<0.05)$, and a significant correlation was found with the duration of the activity $(r=0.82, p<0.05)$.

The results of the numerical simulations of the deposition density rates (particle number $/ \mathrm{cm}^{2} / \mathrm{min}$ ) of the inhaled particles within different anatomical regions of the airways are summarized in Fig. 4. The majority of the measured particles were in the range of a few hundred-nanometer diameters. As a result, the number of particles deposited in unit time was the highest in the acinar region. Number deposition density rates were on average $1.5 \times 10^{5}$ times higher in the extrathoracic airways than in the lungs (bronchial + acinar).

\section{Discussion}

The main finding of the study is that HCP activity exerts significant effects on hospital patient room aerosol particle size and concentration distribution.

Nursing home patients are at the highest risk of SARS-CoV-2 infection, especially when sharing rooms with roommates of undiagnosed infection [14]. Individual patient rooms could lower the risk of infection and early screening plays a significant role in controlling disease spread. The present setup was designed for nursing care or critically ill patients needing full medical and nursing care. We performed aerosol change measurements in a realworld hospital setting. Our measurements were performed on the adjacent bed, where a potential roommate could inhale from the room air particles released by the other patient and disturbed by different HCP activities [27]. It is important to emphasize that activities requiring at least $2 \mathrm{HCPs}$ (eg., caring for obese patients) were associated with higher particle concentration.

Once airborne particles carrying the SARS-CoV-2 virus are exhaled, the risk for infection of a roommate is influenced by several factors, among which the concentration of airborne particles carrying the virus and their deposition in the respiratory system are of special importance. We found that daytime activities of $\mathrm{HCP}$ and patients are resulting in a constant increase in the number of submicron particles, whereas supermicron particle number changes represent more 
Fig. 4 Extrathoracic, bronchial, and acinar deposition density rates of the number of inhaled aerosol particles in the studied patient room. A All anatomical regions. B Extrathoracic airways. C Bronchial region. D Acinar region. Note the logarithmic vertical scale of the top-left summary plot. Calculated Pearson correlation coefficients with two-tailed test of significance: $\boldsymbol{r}=0.972$, $\mathbf{p}<0.05 ; \mathbf{q}=0.977$, $\mathbf{p}<0.05 ; \mathbf{\phi} r=0.999$, $\mathbf{p}<0.05$
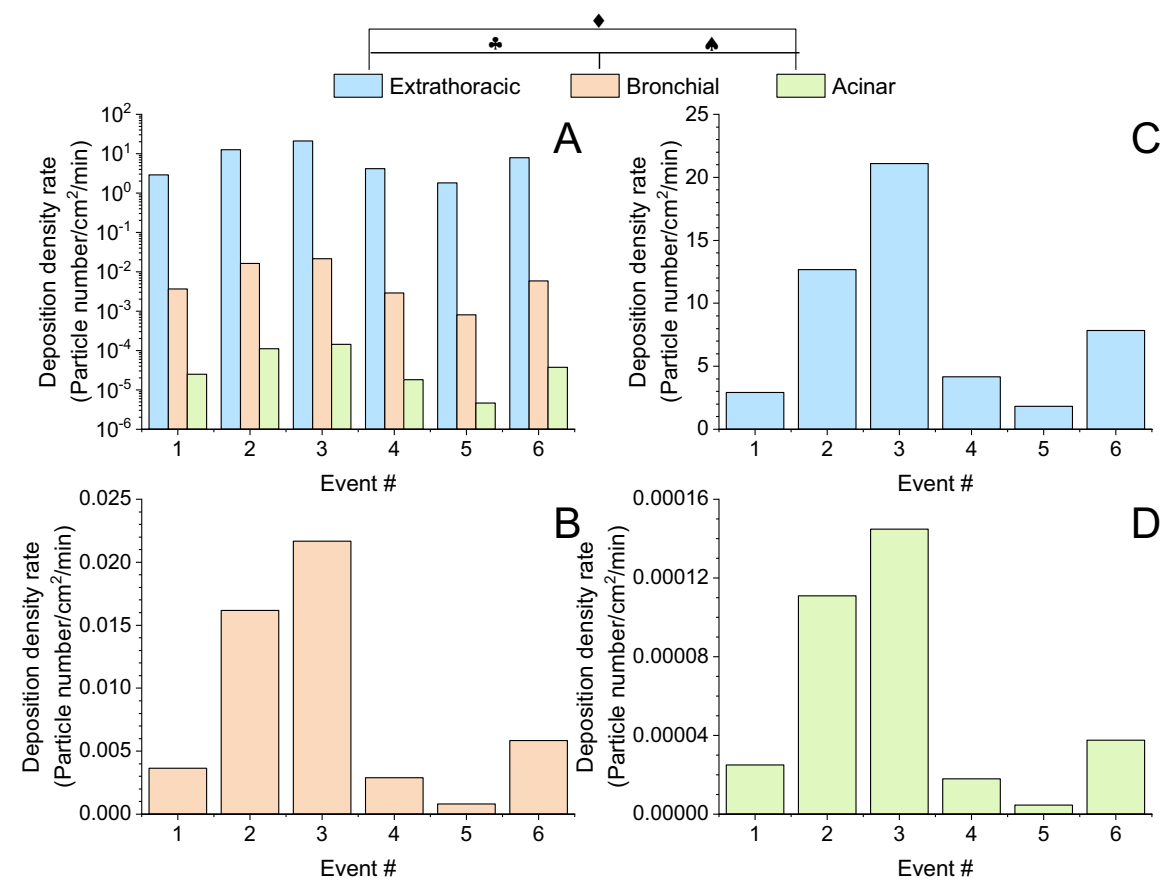

distinct peaks followed by a rapid decay. Nighttime without significant activity was associated with a low-level concentration in sub- and supermicron aerosol particles.

There are many known medical interventions (e.g., tracheal intubation, tracheotomy, cardiopulmonary resuscitation, bronchoscopy, and sputum induction) that result in significant increases in the generation and release of airborne particles [37, 38]. Recent studies show that among the aerosol-generating procedures, high-flow oxygen therapy and non-invasive ventilation are also associated with a significant increase in the release of airborne particles and consequential viral spread around patients in need of these therapeutic interventions [39].

While the focus of our study was the characterization of particle generation and deposition associated with the activities of HCP, we also identified particle emissions that were attributed to the patient's activity. It is now widely recognized that individuals emit particles during coughing, sneezing, loud speaking, singing, or normal breathing [40]. While the amount of exhaled particles varies several orders of magnitudes between human subjects, it has been shown in a recent study [41] that individuals can be categorized into two distinct groups by means of aerosol particle emission rate. The high-producers $(18 \%$ of the examined group) were responsible for $80 \%$ of the exhaled particles, while the low-producers emitted a significantly lower amount. The inhalation of isotonic saline can significantly reduce the number of exhaled particles among the high-producer subjects for up to $6 \mathrm{~h}$ after inhalation [42]. These results suggest that the particle emission of $\mathrm{C}$ category events (patient's activity, coughing, sneezing, etc.) might be reduced by inhalation of isotonic saline, reducing the associated risks of airborne infections of roommates. Air movements caused by the opening of doors and windows might also influence the concentration and deposition of airborne particles in hospital and nursing home settings.

Particles inhaled from the room air deposit in different parts of airways and lungs, and if carrying the virus, this contributes to the spread of COVID-19 among hospitalized or nursing home residents [43]. How particles deposit is determined by the size, composition, concentration, and coagulation of the particles as well as the influence of external factors (e.g., physical forces, such as air movement). In line with previous results [44], larger particles deposit in the upper airways, while small particles enter acinar regions of the lungs. Deposition density was higher for the acinar region during patient activities (might include cough, position change in the bed, etc.). 
Airway deposition simulations demonstrated that the number of particles depositing in the airways and the probability of infection depends on the type of activity. In addition, the distribution of particles among different anatomical regions is also a function of the activity type. We found that HCP activities are predominantly associated with changes in supermicron airborne particles, which deposit mainly in the upper airways. Similarly, higher physical activity in classrooms or offices also affects larger airborne particles. Activities generating a higher number of small particles lead to higher lung acinar deposition.

Generally, the higher the concentration of the particles associated with a certain activity, the higher the probability of infection. Simulations show that for one $\mathrm{cm}^{2}$ of airway epithelium, more particles are deposited in the extrathoracic airways. This can explain why frequent early symptoms of the SARSCoV-2 are sore throat and loss of taste and smell [45]. These results also suggest the opportunity for oral administration of aerosolized disinfectants, antiviral treatment, or even corticosteroids with smaller particle sizes (ciclesonide and beclomethasone) to avoid severe disease [46]. The data suggest that a bedridden roommate's activities increase airborne particles in the sub-micron range, which likely promote the acinar entry of possible infective agents. This might partially explain the rapid spread of COVID-19 pneumonia in nursing homes and hospital settings which still represents a high risk for unvaccinated individuals [19].

The actual amount of virus to which a roommate is exposed is also influenced by the virus content of the individual particles, the decreases in the concentration of virus-carrying airborne particles (e.g., due to falling of larger respiratory droplets to the ground) and loss of viability and infectiousness of the virus carried by the airborne particles due to high temperature, and ultraviolet radiation (e.g., sunlight).

\section{Limitations of the study}

Airborne particle is a general term for all the measured sub-visible matter suspended in the air. Indoor air contains a variety of different airborne particles, which cover a spectrum of different sizes. In addition to respiratory droplets and particles emitted from the patient, these also include particles of dust and dirt as well as other microorganisms. Studies conducted in cleanrooms demonstrated that personnel are the main contributors to particles. It is a major limitation of our study that we did not have the opportunity to assess the physical properties or the virus content of the airborne particles. Furthermore, the optical particle counter we used in this study is size-calibrated with PSL particles, which is a widely accepted calibration method in case of general airborne particles. Although the optical properties of the exhaled particles generated in the lungs differ from the optical properties of PSL spheres, they may stick to other airborne particles producing a mixture with barely predictable optical properties, which may affect the cutoff diameters of the instrument, resulting in slightly distorted size distributions. However, this limitation does not affect our conclusions. Thus, further studies are warranted to assess the effects of HCP activity on actual viral transmission by very small fine respiratory droplets and aerosol particles that contain an infectious virus.

We also did not have the opportunity to record voice and images, with which the description of the patient's activities could have been refined. It is important to note that in the case of patients needing oxygen therapy, the constant flow of the therapeutic gas might significantly influence particle distribution. Additionally, changes in the distance between roommates can also influence aerosol particle traffic and deposition but were not measured as a variable. Additional measurements are also needed to evaluate external influences in nursing home or hospital room settings.

\section{Conclusions}

Our experimental setup made it possible to closely monitor the interaction between HCPs and a COVID19 patient in a hospital ward and its effect on environmental airborne particle changes. Our data confirm the need for more data describing these changes, especially as they may be crucial for a better understanding of nursing home or hospital-acquired airborne transmission of SARS-CoV-2, a well-known but not fully understood safety issue in the care of the elderly. A better understanding of the generation, release, and movement of airborne particles in a closed room leads to a better understanding of how potentially virus-carrying particles contribute to airborne transmission of SARS-CoV-2 in hospitals and 
long-term care facilities. Gaining this knowledge also provides the potential to develop new methods to prevent the release and/or effectively remove these airborne particles and establish a healthier air environment.

Personal protective equipment and strict protocols aim to minimize the chance of infection of HCP and other individuals [47, 48]. Social distancing could contribute to lowering the spread of airborne transmitted diseases, including COVID-19 [49], but in nursing homes and other long term care facilities and hospitals, its implementation proved to be challenging. Proper air filtration and adequate control of air movement are also essential to prevent airborne transmission of SARS-CoV-2 in hospital rooms and long term care facilities housing older individuals at risk of COVID-19 infection. In the early phase of the pandemic, negative pressure patient rooms were optimal to protect HCPs from infection [50]. In contrast, positive pressure rooms are used for severely immunocompromised patients to protect them from infections. In this case, the positive pressure might press the particles down close to the floor and protect the individual from inhaling the invisible particle disturbance caused by the treating medical staff [51]. Measures, including the optimal positioning of patient beds, proper ventilation of hospital rooms, and minimizing of the activities that significantly increase the risk of infected particle inhalation, need to be investigated. Air exchange rates should also be monitored and controlled. Adequate air changes dilute potential viruscarrying airborne particles to an acceptable concentration. It is also very informative to determine the time needed for a patient room to return to the static condition with acceptable airborne particle concentration following a high respiratory particle generating event.

Acknowledgements We are grateful to all HCPs working at the COVID-19 ward, the patient, and the relatives for making this work possible.

Funding Open access funding provided by ELKH Wigner Research Centre for Physics. This research was supported by the COVID-19 flagship project of the Centre for Energy Research (ID: 127), and the Eötvös Loránd Research Network (grant number: SA-45/2021)

\section{Declarations}

Competing interests The authors declare no competing interests.
Open Access This article is licensed under a Creative Commons Attribution 4.0 International License, which permits use, sharing, adaptation, distribution and reproduction in any medium or format, as long as you give appropriate credit to the original author(s) and the source, provide a link to the Creative Commons licence, and indicate if changes were made. The images or other third party material in this article are included in the article's Creative Commons licence, unless indicated otherwise in a credit line to the material. If material is not included in the article's Creative Commons licence and your intended use is not permitted by statutory regulation or exceeds the permitted use, you will need to obtain permission directly from the copyright holder. To view a copy of this licence, visit http://creativecommons.org/licenses/by/4.0/.

\section{References}

1. Nikolich-Zugich J, Knox KS, Rios CT, Natt B, Bhattacharya D, Fain MJ. SARS-CoV-2 and COVID-19 in older adults: what we may expect regarding pathogenesis, immune responses, and outcomes. Geroscience. 2020;42:505-14.

2. Coronavirus Resource Center, Johns Hopkins University; https://coronavirus.jhu.edu/map.html (accessed on $12 / 13 / 2021$ )

3. Distribution of total COVID-19 deaths in the United States as of October 7, 2021, by age group. https://www. statista.com/statistics/1254488/us-share-of-total-coviddeaths-by-age-group/ (accessed on 10/13/2021)

4. Centers for Disease Control And Prevention: Scientific Brief: SARS-CoV-2 Transmission; https://www.cdc. gov/coronavirus/2019-ncov/science/science-briefs/sarscov-2-transmission.html (accessed on 10/13/2021)

5. Gesellschaftfür Aerosolforschung e.V. (2020). Position paper of the Gesellschaft für Aerosolforschung on understanding the role of aerosol particles in SARSCoV-2 infection. Zenodohttps://doi.org/10.5281/zenodo. 4350494

6. Johnstone J, Millar J, Lelic A, Verschoor CP, Walter SD, Devereaux PJ, Bramson J, Loeb M. Immunosenescence in the nursing home elderly. BMC Geriatr. 2014;14:50.

7. Johnstone J, Parsons R, Botelho F, Millar J, McNeil S, Fulop T, McElhaney J, Andrew MK, Walter SD, Devereaux PJ, Malekesmaeili M, Brinkman RR, Mahony $\mathrm{J}$, Bramson J, Loeb M. Immune biomarkers predictive of respiratory viral infection in elderly nursing home residents. PLoS One. 2014;9:e108481.

8. Johnstone J, Parsons R, Botelho F, Millar J, McNeil S, Fulop T, McElhaney JE, Andrew MK, Walter SD, Devereaux PJ, Malek M, Brinkman RR, Bramson J, Loeb M. T-Cell Phenotypes predictive of frailty and mortality in elderly nursing home residents. J Am Geriatr Soc. 2017;65:153-9.

9. Bencivenga L, Rengo G, Varricchi G. Elderly at time of COronaVIrus disease 2019 (COVID-19): possible role of immunosenescence and malnutrition. Geroscience. 2020;42:1089-92.

10. Pietrobon AJ, Teixeira FME, Sato MN. Immunosenescence and inflammaging: risk factors of 
severe COVID-19 in older people. Front Immunol. 2020;11:579220.

11. Promislow DEL. A geroscience perspective on COVID-19 mortality. J Gerontol A Biol Sci Med Sci. 2020;75:e30-3.

12. Carnahan JL, Lieb KM, Albert L, Wagle K, Kaehr E, Unroe KT. COVID-19 disease trajectories among nursing home residents. J Am Geriatr Soc. 2021;69:2412-8.

13. Das Gupta D, Kelekar U, Turner SC, Sule AA, Jerman TG. Interpreting COVID-19 deaths among nursing home residents in the US: the changing role of facility quality over time. PLoS One. 2021;16:e0256767.

14. Grabowski DC, Mor V. Nursing home care in crisis in the wake of COVID-19. JAMA. 2020;324:23-4.

15. Shen K, Loomer L, Abrams H, Grabowski DC, Gandhi A. Estimates of COVID-19 cases and deaths among nursing home residents not reported in federal data. JAMA Netw Open. 2021;4:e2122885.

16. Cangiano B, Fatti LM, Danesi L, Gazzano G, Croci M, Vitale G, Gilardini L, Bonadonna S, Chiodini I, Caparello CF, Conti A, Persani L, Stramba-Badiale M, Bonomi M. Mortality in an Italian nursing home during COVID-19 pandemic: correlation with gender, age, ADL, vitamin D supplementation, and limitations of the diagnostic tests. Aging (Albany NY). 2020;12:24522-34.

17. Husebo BS, Berge LI. Intensive medicine and nursing home care in times of SARS CoV-2: a Norwegian perspective. Am J Geriatr Psychiatry. 2020;28:792-3.

18. Kaiser Family Foundation: State COVID-19 aata and policy actions. Metrics in Long-Term Care Facilities. https://www.kff.org/coronavirus-covid-19/issue-brief/ state-covid-19-data-and-policy-actions/\#longtermcare (accessed on 10/13/2021)

19. Kemenesi G, Kornya L, Toth GE, Kurucz K, Zeghbib S, Somogyi BA, Zoldi V, Urban P, Herczeg R and Jakab F. Nursing homes and the elderly regarding the COVID-19 pandemic: situation report from Hungary. Geroscience. 2020:1-7

20. Long-term-care COVID tracker. https://covidtracking. com/nursing-homes-long-term-care-facilities (accessed on 10/13/2021)

21. Ma HM, Ip M, Hui E, Chan PK, Hui DS, Woo J. Role of atypical pathogens in nursing home-acquired pneumonia. J Am Med Dir Assoc. 2013;14:109-13.

22. El-Solh AA, Niederman MS, Drinka P. Nursing homeacquired pneumonia: a review of risk factors and therapeutic approaches. Curr Med Res Opin. 2010;26:2707-14.

23. Boockvar KS, Gruber-Baldini AL, Stuart B, Zimmerman $\mathrm{S}$, Magaziner J. Medicare expenditures for nursing home residents triaged to nursing home or hospital for acute infection. J Am Geriatr Soc. 2008;56:1206-12.

24. Gomolin IH and Kathpalia RK. Influenza. How to prevent and control nursing home outbreaks. Geriatrics. 2002;57:28-30, 33-4

25. Naughton BJ, Mylotte JM, Tayara A. Outcome of nursing home-acquired pneumonia: derivation and application of a practical model to predict 30 day mortality. J Am Geriatr Soc. 2000;48:1292-9.

26. Sahu AK, Amrithanand VT, Mathew R, Aggarwal P, Nayer J, Bhoi S. COVID-19 in health care workers - a systematic review and meta-analysis. Am J Emerg Med. 2020;38:1727-31.
27. Iversen $\mathrm{K}$, Bundgaard $\mathrm{H}$, Hasselbalch $\mathrm{RB}$, Kristensen JH, Nielsen PB, Pries-Heje M, Knudsen AD, Christensen CE, Fogh K, Norsk JB, Andersen O, Fischer TK, Jensen CAJ, Larsen M, Torp-Pedersen C, Rungby J, Ditlev SB, Hageman I, Mogelvang R, Hother CE, Gybel-Brask M, Sorensen E, Harritshoj L, Folke F, Sten C, Benfield T, Nielsen SD, Ullum H. Risk of COVID-19 in health-care workers in Denmark: an observational cohort study. Lancet Infect Dis. 2020;20:1401-8.

28. Sikkema RS, Pas SD, Nieuwenhuijse DF, O'Toole A, Verweij J, van der Linden A, Chestakova I, Schapendonk C, Pronk M, Lexmond P, Bestebroer T, Overmars RJ, van Nieuwkoop S, van den Bijllaardt W, Bentvelsen RG, van Rijen MML, Buiting AGM, van Oudheusden AJG, Diederen BM, Bergmans AMC, van der Eijk A, Molenkamp R, Rambaut A, Timen A, Kluytmans J, Oude Munnink BB, Kluytmans van den Bergh MFQ and Koopmans MPG. COVID-19 in health-care workers in three hospitals in the south of the Netherlands: a cross-sectional study. Lancet Infect Dis. 2020;20:1273-1280

29. Navaratnam AV, Gray WK, Day J, Wendon J, Briggs TWR. Patient factors and temporal trends associated with COVID-19 in-hospital mortality in England: an observational study using administrative data. Lancet Respir Med. 2021;9:397-406.

30. Rivett L, Sridhar S, Sparkes D, Routledge M, Jones NK, Forrest S, Young J, Pereira-Dias J, Hamilton WL, Ferris M, Torok ME, Meredith L, Collaboration C-NC-B, Curran MD, Fuller S, Chaudhry A, Shaw A, Samworth RJ, Bradley JR, Dougan G, Smith KG, Lehner PJ, Matheson NJ, Wright G, Goodfellow IG, Baker S and Weekes MP. Screening of healthcare workers for SARS-CoV-2 highlights the role of asymptomatic carriage in COVID-19 transmission. Elife. 2020;9

31. Hofmann W, Koblinger L. Monte-Carlo Modeling of aerosol deposition in human lungs 3 Comparison with Experimental-Data. J Aerosol Sci. 1992;23:51-63.

32. Koblinger L, Hofmann W. MonteCarlo Modeling of Aerosol Deposition in Human Lungs 1 Simulation of particletransport in a stochastic lung structure. J Aerosol Sci. 1990;21:661-74.

33. Hofmann W, Koblinger L. Monte-Carlo Modeling of Aerosol Deposition in Human Lungs 2 Deposition fractions and their sensitivity to parameter variations. J Aerosol Sci. 1990;21:675-88.

34. ICRP Publication 66. Human respiratory tract model for radiological protection, Ann. ICRP 24. Pergamon Press. 1994

35. Farkas A, Jokay A, Balashazy I, Furi P, Muller V, Tomisa G, Horvath A. Numerical simulation of emitted particle characteristics and airway deposition distribution of Symbicort((R)) Turbuhaler((R)) dry powder fixed combination aerosol drug. Eur J Pharm Sci. 2016;93:371-9.

36. Horvath A, Farkas A, Szipocs A, Tomisa G, Szalai Z, Galffy G. Numerical simulation of the effect of inhalation parameters, gender, age and disease severity on the lung deposition of dry powder aerosol drugs emitted by Turbuhaler(R), Breezhaler(R) and Genuair(R) in COPD patients. Eur J Pharm Sci. 2020;154:105508.

37. Simpson JP, Wong DN, Verco L, Carter R, Dzidowski M, Chan PY. Measurement of airborne particle exposure 
during simulated tracheal intubation using various proposed aerosol containment devices during the COVID-19 pandemic. Anaesthesia. 2020;75:1587-95.

38. Klompas M, Baker M, Rhee C. What is an aerosol-generating procedure? JAMA Surg. 2021;156:113-4.

39. Hui DS, Chow BK, Lo T, Tsang OTY, Ko FW, Ng SS, Gin $\mathrm{T}$ and Chan MTV. Exhaled air dispersion during high-flow nasal cannula therapy versus CPAP via different masks. Eur Respir J. 2019;53

40. Scheuch G. Breathing is enough:for the spread of influenza virus and SARS-CoV-2 by breathing only. J Aerosol Med Pulm D. 2020;33:230-4.

41. Edwards DA, Ausiello D, Salzman J, Devlin T, Langer R, Beddingfield BJ, Fears AC, Doyle-Meyers LA, Redmann RK, Killeen SZ, Maness NJ and Roy CJ. Exhaled aerosol increases with COVID-19 infection, age, and obesity. Proc Natl Acad Sci U S A. 2021;118

42. Edwards DA, Man JC, Brand P, Katstra JP, Sommerer K, Stone HA, Nardell E, Scheuch G. Inhaling to mitigate exhaled bioaerosols. Proc Natl Acad Sci U S A. 2004;101:17383-8.

43. Facts about healthcare-associated infections in long-term care facilities. Accessed April 11, 2021. https://www. ecdc.europa.eu/en/healthcare-associated-infections-longterm-care-facilities/facts

44. Madas BG, Furi P, Farkas A, Nagy A, Czitrovszky A, Balashazy I, Schay GG, Horvath A. Deposition distribution of the new coronavirus (SARS-CoV-2) in the human airways upon exposure to cough-generated droplets and aerosol particles. Sci Rep. 2020;10:22430.

45. Sakalli E, Temirbekov D, Bayri E, Alis EE, Erdurak SC, Bayraktaroglu M. Ear nose throat-related symptoms with a focus on loss of smell and/or taste in COVID-19 patients. Am J Otolaryngol. 2020;41:102622.

46. Miyazawa D, Kaneko G. Clinical trials of inhaled beclomethasone and mometasone for COVID-19 should be conducted. J Med Virol. 2021;93:637-8.

47. Ippolito M, Vitale F, Accurso G, Iozzo P, Gregoretti C, Giarratano A, Cortegiani A. medical masks and respirators for the protection of healthcare workers from SARSCoV-2 and other viruses. Pulmonology. 2020;26:204-12.

48. Ferioli M, Cisternino C, Leo V, Pisani L, Palange P and Nava S. Protecting healthcare workers from SARS-CoV-2 infection: practical indications. Eur Respir Rev. 2020;29

49. Voko Z, Pitter JG. The effect of social distance measures on COVID-19 epidemics in Europe: an interrupted time series analysis. Geroscience. 2020;42:1075-82.

50. Santarpia JL, Rivera DN, Herrera VL, Morwitzer MJ, Creager HM, Santarpia GW, Crown KK, Brett-Major DM, Schnaubelt ER, Broadhurst MJ, Lawler JV, Reid SP, Lowe JJ. Aerosol and surface contamination of SARSCoV-2 observed in quarantine and isolation care. Sci Rep. 2020;10:12732.

51. Qian H, Zheng X. Ventilation control for airborne transmission of human exhaled bio-aerosols in buildings. J Thorac Dis. 2018;10:S2295-304.

Publisher's note Springer Nature remains neutral with regard to jurisdictional claims in published maps and institutional affiliations. 